\title{
The genes encoding virulence-associated proteins and the capsule of Streptococcus pneumoniae are upregulated and differentially expressed in vivo
}

\author{
A. David Ogunniyi, Philippe Giammarinaro and James C. Paton
}

Department of Molecular Biosciences, Adelaide University, Adelaide, South Australia 5005, Australia Author for correspondence: James C. Paton. Tel: +61 8 83035929. Fax: +61 883033262.
e-mail: james.paton@adelaide.edu.au

The polysaccharide capsule of Streptococcus pneumoniae and several wellcharacterized virulence proteins are known to contribute to the pathogenesis of pneumococcal disease. However, there is a paucity of data on the expression of their respective genes in vivo. In this study, the relative abundance of the mRNA transcripts of the genes encoding pneumolysin ( $p / y)$, pneumococcal surface protein $A$ (pspA), pneumococcal surface antigen $A$ (psaA) and cholinebinding protein $A(c b p A)$, and of the first gene of the capsular polysaccharide biosynthesis locus (cps2A), was measured in virulent type 2 pneumococci harvested from the blood of BALB/c mice at $12 \mathrm{~h}$ and $24 \mathrm{~h}$ following intraperitoneal infection. The mRNA levels were then compared, using relative quantitative RT-PCR, with those present in organisms grown in serum broth. The expression of ply was upregulated threefold at $12 \mathrm{~h}$, and 10-fold at $24 \mathrm{~h}$ post-infection; the expression of pspA and psaA was upregulated threefold and fivefold, respectively, at $12 \mathrm{~h}$ post-infection. Interestingly, the expression of pspA was 36-fold higher at $24 \mathrm{~h}$ post-infection whereas the expression of cps2A was upregulated approximately fourfold at 12 and $24 \mathrm{~h}$ post-infection. However, cbpA mRNA levels remained comparable in vivo and in vitro. When organisms were grown in whole blood or THY broth, the relative expression of these genes in the two growth media also differed markedly. This work provides direct molecular evidence that known virulence-associated genes of S. pneumoniae are differentially expressed in vivo. Data on the relative expression of these genes in different growth media also suggests that the regulation of expression of these genes is highly complex and multifactorial.

Keywords: pneumococcus, pneumolysin, surface proteins, mRNA, quantitative RT-PCR

\section{INTRODUCTION}

Streptococcus pneumoniae is a very important human pathogen, causing a spectrum of diseases including pneumonia, meningitis, bacteraemia and otitis media (Musher, 1992; Tuomanen et al., 1995). The incidence of pneumococcal disease is particularly high in children under the age of 5 years, the elderly and immunocompromised individuals (Garenne et al., 1992; World Health Organization, 1997). S. pneumoniae is conservatively estimated to cause over 1 million deaths in children under 5 years of age in developing countries each year

Abbreviation: PS, polysaccharide.
(World Health Organization, 1997). Furthermore, the alarming rate at which this organism is acquiring resistance to multiple antimicrobials has exacerbated the high morbidity and mortality resulting from pneumococcal disease (Whitney et al., 2000).

The polysaccharide (PS) capsule is strongly anti-phagocytic and is a sine qua non of pneumococcal virulence (Austrian, 1981). There are 90 recognized PS serotypes; synthesis of the serotype-specific capsular PS is encoded by distinct clusters of up to 20 tightly linked genes transcribed as single operons (Paton \& Morona, 2000). Antibodies to the PS are highly protective, and the global impact of pneumococcal disease has led to the development of polyvalent PS and PS-protein conjugate 
vaccine formulations. Although appreciable levels of success have been achieved with these vaccination strategies, the problems of serotype specificity of protection, geographical and temporal variations in serotype distribution, cost of vaccine formulations, and the possibility of nasopharyngeal replacement of vaccine serotypes by non-vaccine serotypes in vaccinated individuals still exist (Obaro, 2000). For this reason, we and others have been investigating the capacity of pneumococcal virulence proteins, administered either singly or in combination, to elicit non-serotype-dependent protection against pneumococcal disease (Alexander et al., 1994; Briles et al., 2000a, b; Ogunniyi et al., 2000).

The pneumococcal virulence proteins which have received the greatest attention to date are the thiolactivated toxin pneumolysin (Ply) (for reviews see Boulnois et al., 1991; Boulnois, 1992; Paton, 1996; Paton et al., 1993), two choline-binding surface proteins called pneumococcal surface protein A (PspA) (Yother \& Briles, 1992) and choline-binding protein A (CbpA) (also referred to as PspC or SpsA) (Brooks-Walter et al., 1999; Hammerschmidt et al., 1997; Rosenow et al., 1997), and a metal-binding lipoprotein called pneumococcal surface antigen A (PsaA) (Berry \& Paton, 1996; Dintilhac et al., 1997; Paton, 1998). These proteins possess a range of biological activities, indicating that they act at different stages of the pathogenic process. Ply, for instance, has both direct cytotoxic and complement activation properties, mediated by different domains within the toxin (Boulnois et al., 1991). Apart from directly damaging respiratory epithelium (Feldman et al., 1990), the cytotoxic property accounts for inhibition of specific and non-specific immune responses (Ferrante et al., 1984; Paton \& Ferrante, 1983), as well as stimulation of the release of inflammatory cytokines from host cells (Houldsworth et al., 1994). Direct activation of the classical complement pathway is the result of binding of Ply to the Fc region of IgG, which also contributes to inflammation and depletes serum opsonic activity (Mitchell et al., 1991; Paton et al., 1984). On the other hand, PspA interferes with complement activation and slows the clearance of pneumococci from the blood of infected mice (McDaniel et al., 1987; Tu et al., 1999). Hammerschmidt et al. (1999) have shown that PspA binds lactoferrin, and so it may also function by scavenging iron in the nasopharynx. CbpA is structurally related to PspA, and mediates adherence to cytokine-activated lung cells, as well as playing a major role in colonization of the nasopharynx in an infant rat model (Rosenow et al., 1997). It has also been shown to specifically bind the secretory component of human secretory immunoglubulin A (Hammerschmidt et al., 2000). PsaA forms part of an ABC-type manganese permease complex (Dintilhac et al., 1997) and mutations in $p s a A$ have pleiotropic effects on various pneumococcal functions, including adherence, autolysis and virulence (Berry \& Paton, 1996; Claverys et al., 1999; Novak et al., 1998).

Mutagenesis studies have shown that Ply, PspA, CbpA and PsaA contribute to virulence in a variety of animal models of pneumococcal disease (Berry et al., 1989, 1999; Berry \& Paton, 1996; McDaniel et al., 1987; Rosenow et al., 1997). Moreover, mutagenesis of certain combinations of virulence factor genes results in additive attenuation, implying that their products function independently in virulence (Berry \& Paton, 2000). However, it is not currently known whether any of these genes are coordinately regulated, or whether they are specifically up-regulated in vivo. Moreover, evidence for in vivo expression is largely confined to indirect serological studies (Lankinen et al., 1999; Orihuela et al., 2000; Rapola et al., 2000; Virolainen et al., 2000). In this study, we provide direct molecular evidence for in vivo expression of important pneumococcal virulence factors. The levels of mRNA transcript for each gene have been measured using relative quantitative RT-PCR analysis of total bacterial RNA isolated from the blood of mice at various times after intraperitoneal infection. This has permitted what is to our knowledge the first comparison of the relative kinetics of in vivo expression of proven pneumococcal virulence factors.

\section{METHODS}

Bacterial strain and growth conditions. The bacterial strain used in this study was D39, a virulent encapsulated type $2 S$. pneumoniae strain which has been described previously (Avery et al., 1944). For isolation of in vitro-derived total RNA, and infection of mice, bacteria grown overnight on blood agar were inoculated into serum broth (meat extract broth supplemented with $10 \%$ horse serum) and then grown statically for $3 \mathrm{~h}$ at $37^{\circ} \mathrm{C}$. For extraction of RNA, cells were harvested by centrifugation at $15500 \mathrm{~g}$ for $5 \mathrm{~min}$. For infection of mice, the density of the serum broth bacterial culture was adjusted to $\mathrm{OD}_{600} 0 \cdot 08$, which corresponds to approximately $1 \times 10^{8}$ c.f.u. $\mathrm{ml}^{-1}$. The bacteria were then diluted further to the required c.f.u. in serum broth. As an alternative source of in vitro-derived RNA, pneumococci were subcultured from blood agar into Todd-Hewitt broth supplemented with $0.5 \%$ yeast extract (THY) and incubated statically at $37^{\circ} \mathrm{C}$ to $\mathrm{OD}_{600}$ $0 \cdot 3$. An aliquot $(1.5 \mathrm{ml})$ of this culture was then centrifuged at $15500 \mathrm{~g}$ for $5 \mathrm{~min}$ to pellet the bacteria. In another experiment, bacteria grown overnight on blood agar were subcultured into fresh whole blood obtained from naïve mice and incubated for $3 \mathrm{~h}$ at $37^{\circ} \mathrm{C}$.

Infection of mice and harvesting of bacteria for RNA isolation. Two groups of twenty-four 6-8-week-old male $\mathrm{BALB} / \mathrm{c}$ mice were infected intraperitoneally with approximately $1 \times 10^{3}$ c.f.u. of D39. Mice were exsanguinated after $12 \mathrm{~h}$ or $24 \mathrm{~h}$ by cardiac puncture under deep anaesthesia, and blood obtained from each group of mice was pooled into sterile heparinized tubes on ice. The bacteria were harvested from the blood by initial centrifugation at $825 \mathrm{~g}$ at $4{ }^{\circ} \mathrm{C}$ for $5 \mathrm{~min}$ to pellet erythrocytes and leucocytes. The resulting supernatant, consisting of a mixture of plasma, bacteria and thrombocytes, was then centrifuged at $15500 \mathrm{~g}$ at $4{ }^{\circ} \mathrm{C}$ for 5 min to pellet the bacterial cells. The supernatant was discarded and RNA was extracted from the bacterial pellet. The same procedure was used to harvest bacteria grown in fresh whole blood obtained from naïve mice.

RNA isolation. Total RNA was extracted from in vitro- and in vivo-harvested bacteria by a modification of the method of Mortier-Barrière et al. (1998). The bacterial pellet was resuspended completely in $300 \mu$ l prewarmed $\left(65^{\circ} \mathrm{C}\right)$ acid- 
Table 1. Oligonucleotide primers

\begin{tabular}{|c|c|c|}
\hline Primer & Sequence $\left(5^{\prime} \rightarrow 3^{\prime}\right)$ & Gene sequence reference* \\
\hline ply (forward) & GATGGCAAATAAAGCAGTAAATGACT & Walker et al. (1987) \\
\hline ply (reverse) & TGATGCCACTTAGCCAACAAATCG & \\
\hline $\operatorname{psp} A$ (forward) & CAGAAGAATCTCCCGTAGCCAGT & Yother \& Briles (1992) \\
\hline$p s p A$ (reverse) & CTGGTGCTTTTTGTTTAGCTTCTTCTG & \\
\hline psaA (forward) & GGTACATTACTCGTTCTCTTTCTTTCT & Berry \& Paton (1996) \\
\hline psaA (reverse) & GTGTGGGTCTTCTTTTCCTTTTTC & \\
\hline $\operatorname{cbp} A$ (forward) & GAAAACGAAGGAAGTACCCAAGCA & Rosenow et al. (1997) \\
\hline$c b p A$ (reverse) & СТTTAACTTTCACATCGAACTCAGC & \\
\hline $\operatorname{cps} 2 A$ (forward) & AGTGGTAACTGCGTTAGTCC & Iannelli et al. (1999) \\
\hline $\operatorname{cps} 2 A$ (reverse) & CTGCCAAGTAAGACGAACTC & \\
\hline 16S rRNA (forward) & GGTGAGTAACGCGTAGGTAA & Bentley et al. (1991) \\
\hline 16S rRNA (reverse) & ACGATCCGAAAACCTTCTTC & \\
\hline
\end{tabular}

* References are for both forward and reverse primer in each pair.

phenol and incubated for $5 \mathrm{~min}$ at $65^{\circ} \mathrm{C}$. To this, $300 \mu \mathrm{l}$ prewarmed NAES buffer $(50 \mathrm{mM}$ sodium acetate $\mathrm{pH} 5 \cdot 1$, $10 \mathrm{mM}$ EDTA, $1 \%$ SDS) was added, and the mixture was incubated for another $5 \mathrm{~min}$ at $65^{\circ} \mathrm{C}$, with intermittent mixing. The mixture was cooled on ice for $1 \mathrm{~min}$ and the phases were separated by centrifugation at $15500 \mathrm{~g}$ for $1 \mathrm{~min}$. The aqueous phase was re-extracted twice with acid-phenol followed by two further extractions with chloroform. Sodium acetate was added to the resulting supernatant to a final concentration of $300 \mathrm{mM}$ and RNA was then precipitated with 2 vols ethanol at $-20^{\circ} \mathrm{C}$ overnight. The resulting RNA pellet was washed briefly in $70 \%$ ethanol and then resuspended in $50 \mu \mathrm{l}$ nuclease-free water. Recombinant RNasin ribonuclease inhibitor (Promega N251A) was added to a final concentration of $1 \mathrm{U} \mathrm{\mu l}^{-1}$ and the RNA was then treated with

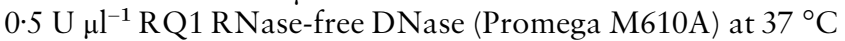
for $30 \mathrm{~min}$. The RNA preparation was then treated with RQ1 DNase stop buffer (Promega M198A) to inactivate the DNase. The purity of the RNA preparation was confirmed by subjecting it to one-step RT-PCR with or without reverse transcriptase, using gene-specific primers (see Table 1). An aliquot of the total RNA sample was also electrophoresed on a $1 \%$ TAE-agarose gel to check for integrity, and then stored at $-70^{\circ} \mathrm{C}$ until required.

RNA quantitation. Levels of mRNA for $p l y, p s p A, p s a A, c b p A$ and $c p s 2 A$ were determined by one-step relative quantitative RT-PCR using the Promega Access RT-PCR system (Promega Biotech, cat. no. A1250). The specific primers used for the various RT-PCR assays are listed in Table 1. As an internal control, primers specific for the $16 \mathrm{~S}$ rRNA were used. Each primer was used at a final concentration of $3 \cdot 3 \mu \mathrm{M}$, except for $16 \mathrm{~S}$ rRNA primers, which were used at a final concentration of $0.04 \mu \mathrm{M}$. This was necessary because of the high abundance of $16 \mathrm{~S}$ rRNA in total RNA extracts. At the lower primer concentration, RT-PCR product intensity was linearly related to RNA concentration. To eliminate the possibility of interference between gene-specific and internal control primers, separate RT-PCR reactions were set up (on ice) from a master mix differing only in the constituent primers. The mix was then aliquoted into tubes held on ice and containing the respective upstream and downstream primers, and thoroughly mixed by gentle vortexing. Each mix was finally aliquoted into thin-walled $0.5 \mathrm{ml}$ reaction tubes and placed in a thermal cycler. The RT-PCR cycling conditions comprised one cycle at $48^{\circ} \mathrm{C}$ for $45 \mathrm{~min}$ (for first-strand cDNA synthesis) one cycle at $94^{\circ} \mathrm{C}$ for $2 \mathrm{~min}$ (for AMV reverse transcriptase inactivation and RNA/cDNA/primer denaturation) followed by 30 cycles of PCR amplification comprising denaturation $\left(94^{\circ} \mathrm{C}\right.$ for $30 \mathrm{~s})$, primer annealing $\left(60^{\circ} \mathrm{C}\right.$ for $\left.30 \mathrm{~s}\right)$, and extension $\left(68^{\circ} \mathrm{C}\right.$ for $45 \mathrm{~s})$.

The linear range of amplification for each RNA preparation was determined separately under these conditions by removing replicate tubes from the thermal cycler at cycle 10 and at every subsequent fourth cycle. The reaction products were resolved by electrophoresis on a $2 \%$ TAE-agarose gel (Agarose LE, Roche Molecular Biochemicals) and stained with Sybr Gold (Molecular Probes). They were then scanned at a resolution of $50 \mu \mathrm{m}$ at medium sample intensity on a Bio-Rad FX Molecular Imager connected to an external laser and quantified using Quantity One software. The cycle number was plotted against the log of signal intensity to determine the linear range of amplification for each mRNA species. Amplicon intensity in a given RNA extract was determined at a cycle number within the linear range for each species. Between RNA extracts, intensities of individual mRNA species were corrected with reference to that obtained for the internal $16 \mathrm{~S}$ rRNA control.

\section{RESULTS}

\section{Infection of mice and total RNA isolation}

The intraperitoneal $\mathrm{LD}_{50}$ of the virulent type 2 pneumococcus used in this study (strain D39) for BALB/c mice has been determined previously to be approximately $10^{2}$ c.f.u., with death occurring approximately 3 days post-infection. At higher doses, death occurs much sooner (e.g. less than $12 \mathrm{~h}$ after infection with $10^{7}$ c.f.u.). Typically, the bacterial load reaches approximately $10^{9}-10^{10}$ c.f.u. $\mathrm{ml}^{-1}$ of blood just before death (Benton et al., 1995; Berry et al., 1999). In this study, the number of bacteria in whole blood at the time of collection was very similar in each case, reaching approximately $1 \cdot 0-2 \cdot 0 \times 10^{9}$ c.f.u. $\mathrm{ml}^{-1}$, with approximately $5 \times 10^{8}$ c.f.u. $\mathrm{ml}^{-1}$ recovered from plasma after the initial low-speed centrifugation to remove erythrocytes, etc. Bacteria were recovered from plasma by high-speed 


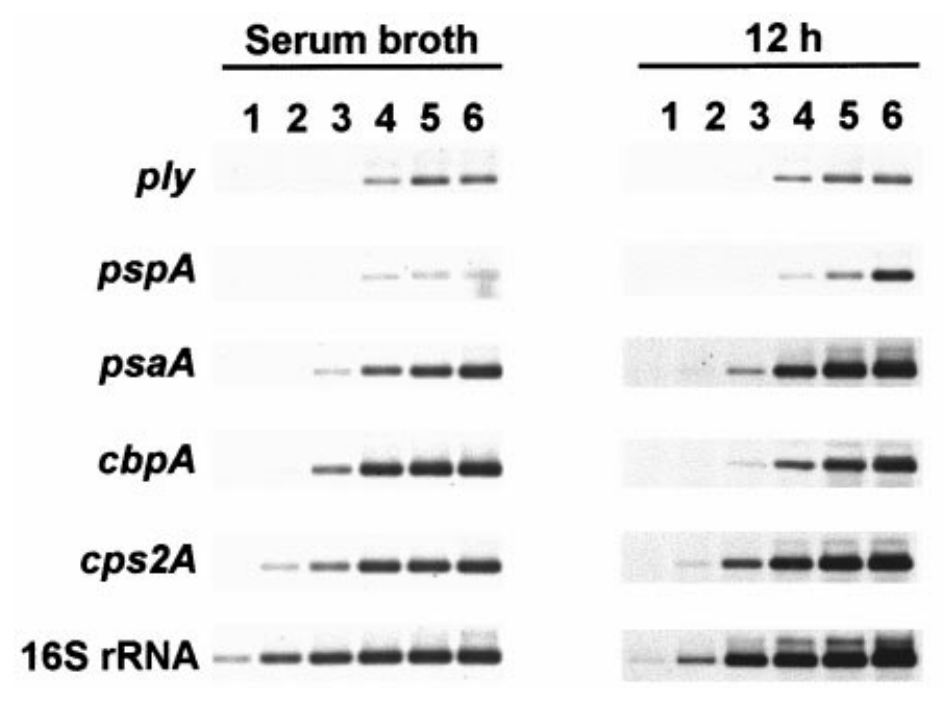

$24 \mathrm{~h}$

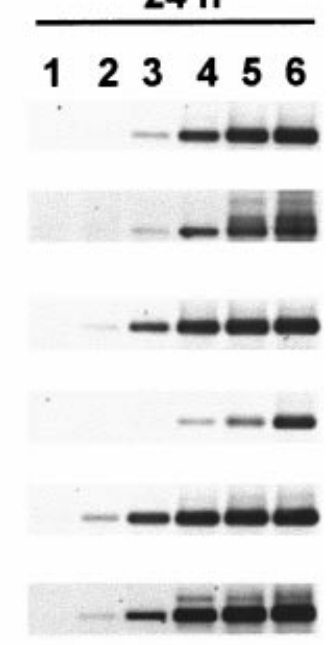

Fig. 1. Agarose gel analyses of virulence gene RT-PCR products from RNA extracted from S. pneumoniae D39 obtained from in vitro (serum broth) culture and from the blood of infected mice at $12 \mathrm{~h}$ and at $24 \mathrm{~h}$ post-infection. Aliquots of RT-PCR products taken after 10, 14, 18, 22, 26, and 30 cycles (lanes 1-6, respectively), are shown for ply, pspA, psaA, cbpA, cps $2 A$, and 16S rRNA as internal control. Samples were electrophoresed on a $2 \%$ agarose gel in TAE buffer and then stained with Sybr Gold.

centrifugation, with a final yield of approximately $10^{8}$ c.f.u. from each ml. Total RNA was then extracted from these bacteria as described in Methods, as well as from bacteria grown to mid-exponential phase in serum broth.

\section{Quantitative comparison of virulence factor mRNA levels}

Relative quantitative RT-PCR was employed to compare the abundance of $c p s 2 A$ (the first gene in the type 2 PS biosynthesis locus), ply, $p s p A, c b p A$ and $p s a A$ mRNAs in total RNA extracts from pneumococci grown in serum broth, or isolated from the blood of mice 12 or $24 \mathrm{~h}$ post-infection (see Methods). This involved quantitation of RT-PCR products after 10, 14, 18, 22, 26, and 30 cycles, and for each assay, determining the period during which the rate of RT-PCR product accumulation was directly related to RNA concentration. By way of illustration, agarose gel analyses for the virulence gene and 16S rRNA RT-PCR products from serum broth, and $12 \mathrm{~h}$ and $24 \mathrm{~h}$ post-infection RNA preparations are shown in Fig. 1. mRNA levels were then expressed relative to that of $16 \mathrm{~S}$ rRNA; $16 \mathrm{~S}$ rRNA was selected as an internal control because rRNAs are known to be maintained at a constant level. The various primer pairs for the virulence genes and rRNA were designed to amplify cDNA fragments of comparable size to ensure similar amplification kinetics. This precludes performing RT-PCR for virulence gene transcripts and rRNA in the same tube. However, reaction tubes were prepared from aliquots of the same master mix to which the different primer pairs were added last. They were then amplified in the same PCR run and electrophoresed on the same gel.

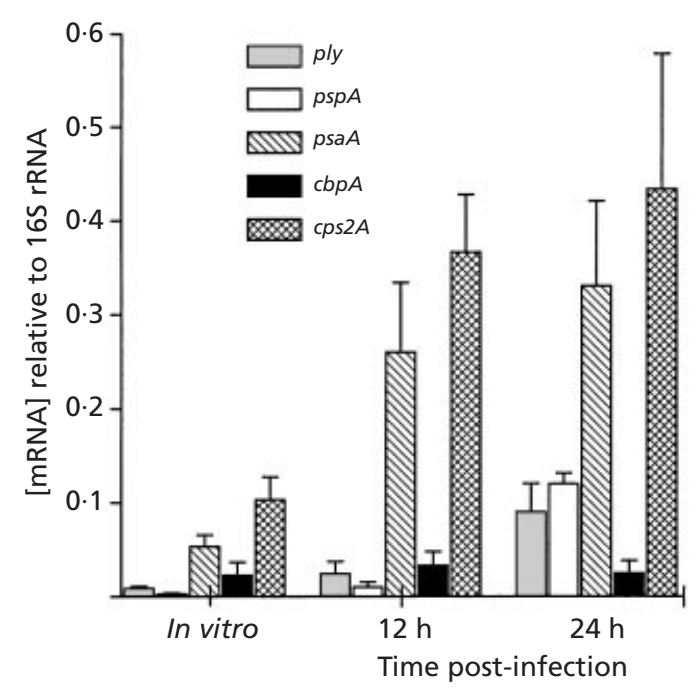

Fig. 2. Relative mRNA concentrations of $p l y, p s p A, p s a A, c b p A$ and $\operatorname{cps} 2 A$ in vitro, and at the indicated times after intraperitoneal infection of mice. Between RNA extracts, intensities of individual mRNA species were corrected with reference to that obtained for the internal $16 \mathrm{~S}$ rRNA control. Data points represent means \pm SE of RT-PCR reactions performed on RNA extracts from bacteria harvested from pooled blood of groups of eight mice from three independent experiments.

The results obtained in the RT-PCR assays using in vitro-derived total RNA as template indicated that the mRNA of $c p s 2 A$ was the most abundant of the species being studied, followed by the mRNAs of $p s a A c b p A$, ply and $p s p A$, in that order (Fig. 2). Similarly, the mRNA of cps $2 A$ was the most abundant of all the virulence genes in in vivo-derived total RNA at each of 
Table 2. Relative in vivo expression of pneumococcal virulence genes

\begin{tabular}{|c|c|c|}
\hline \multirow[t]{2}{*}{ Gene } & \multicolumn{2}{|c|}{$\begin{array}{l}\text { Fold increase relative to in vitro level at indicated } \\
\text { times (significance relative to in vitro level)* }\end{array}$} \\
\hline & $12 \mathrm{~h}$ & $24 \mathrm{~h}$ \\
\hline ply & $2 \cdot 8(\mathrm{NS})$ & $10 \cdot 3(P<0 \cdot 05)$ \\
\hline$p s p A$ & $3 \cdot 1$ (NS) & $36.4(P<0.005)$ \\
\hline$p s a A$ & $4.9(P=0.025)$ & $6.2(P<0.025)$ \\
\hline$c b p A$ & $1 \cdot 4(\mathrm{NS})$ & $1 \cdot 1(\mathrm{NS})$ \\
\hline $\operatorname{cps} 2 \mathrm{~A}$ & $3 \cdot 6(P<0.01)$ & $4.2(P<0.05)$ \\
\hline
\end{tabular}

*Determined using Student's $t$-test (one-tailed); Ns, not significant.

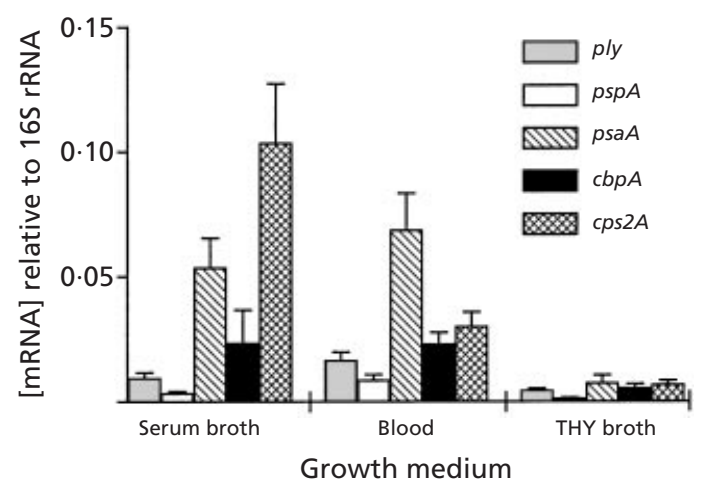

Fig. 3. In vitro expression of $p l y, p s p A, p s a A, c b p A$ and $c p s 2 A$ in different culture media. Data points represent means $\pm S E$ of RT-PCR reactions performed on RNA extracts from bacteria harvested from each culture medium from three independent experiments.

the indicated times post-infection (Fig. 2). However, the mRNA levels of $p s p A$ and ply were higher than that of $c b p A$ at $24 \mathrm{~h}$ post-infection. These results were not due to differences in the efficiency of the various amplification reactions, because each primer pair was designed to operate at identical annealing temperatures, and to direct amplification of a similar size fragment. Moreover, no differences in PCR product intensity were observed when S. pneumoniae D39 chromosomal DNA was used as template (result not shown). Differences were also seen in the concentration of each mRNA species in RNA extracts from in vitro versus in vivo cultures. The mRNA levels for $p l y, p s p A, p s a A$ and cps $2 \mathrm{~A}$ were elevated in bacteria harvested from the blood of mice $12 \mathrm{~h}$ and $24 \mathrm{~h}$ after intraperitoneal infection, compared with bacteria grown in serum broth. Upregulation was particularly pronounced for $p s p A$; its relative mRNA concentration was 36 -fold higher in blood at $24 \mathrm{~h}$ post-infection compared with that in serum broth (Table 2). However, in vivo expression of cbpA was similar to that seen in vitro. At $12 \mathrm{~h}$, upregulation was statistically significant for $p s a A$ and $\operatorname{cps} 2 \mathrm{~A}$, while at $24 \mathrm{~h}$, all genes were significantly upregulated except $c b p A$ (Table 2).

\section{Comparison of virulence factor mRNA levels in different growth media}

The relative expression of the various virulence genes by bacteria grown in serum broth, fresh mouse blood and THY broth was then determined. For each of these culture conditions, bacteria were in mid-exponential phase of growth at the time of harvesting. In general, the expression of the virulence genes was lowest in bacteria grown in THY broth (Fig. 3). The expression of $p s a A$, $p l y$, and $p s p A$ was highest in bacteria grown in fresh blood whereas the levels of $c b p A$ and $c p s 2 A$ mRNAs were highest in serum broth cultures.

\section{DISCUSSION}

The continuing high global morbidity and mortality caused by $S$. pneumoniae, in spite of the availability of antibiotics, and the problems identified with existing vaccination strategies, have prompted extensive research on the pathogenesis of pneumococcal disease. The importance of the PS capsule in virulence has been recognized for more than 70 years (Austrian, 1981), and more recent studies have resulted in the identification and characterization of numerous putative virulence proteins (Paton et al., 1993, 1997). Roles for these proteins in pathogenesis have been proposed on the basis of mutagenesis studies in animal models (Berry \& Paton, 1996, 2000; Brooks-Walter et al., 1999), and several have been shown to be protective immunogens (Alexander et al., 1994; Briles et al., 2000a, b; BrooksWalter et al., 1999). Indeed, vaccines based on combinations of pneumococcal proteins may provide effective, non-serotype-dependent protection against this organism (Briles et al., 2000a, b; Ogunniyi et al., 2000). However, pathogenesis of pneumococcal disease is a complex process and involves a series of interactions between pathogen and host. During the course of an infection, the pneumococcus must adapt to a range of environments (e.g. the nasopharyngeal mucosa, lung mucosa, blood, cerebrospinal fluid, etc.) and optimal survival in any one niche may require expression of a distinct subset of the organism's armoury of potential virulence factors. However, direct molecular evidence for alteration in virulence gene expression in vivo has hitherto been lacking.

In the present study, we have measured and compared the levels of mRNA for four well-characterized virulence protein genes ( $p l y, p s p A, p s a A$ and $c b p A$ ), as well as the first gene in the type 2 PS biosynthesis operon $(c p s 2 A)$ in pneumococci grown in broth culture or isolated from the blood of mice at different times after intraperitoneal infection. This was achieved using relative quantitative RT-PCR, with 16S rRNA as an internal standard. Twelve hours after intraperitoneal infection, the mRNA species of $p l y, p s p A$ and $p s a A$ were up-regulated, unequivocally demonstrating an altered pattern of gene 
expression in vivo vs in vitro. However, the pattern was not constant for the virulence genes during the course of infection. At $24 \mathrm{~h}$, expression of ply and, significantly, $p s p A$, was again increased, but expression of the other virulence factors was not greatly dissimilar to $12 \mathrm{~h}$ levels. These findings clearly show that these virulence genes are not coordinately expressed, under the control of a single global regulatory element.

Interpretation of the significance of differences in virulence-associated gene expression between in vitro and in vivo conditions is complicated, particularly since marked variation in gene expression between cells grown in vitro in THY versus serum broth were observed in the present study. Expression levels in the latter medium were used as a baseline for comparison with expression in blood in vivo, which seems appropriate given that virulence gene expression in pneumococci grown in serum broth was similar to that observed for bacteria grown in whole mouse blood in vitro. Thus, up-regulation of virulence gene expression in pneumococci in the blood of infected mice appears to be largely attributable to host factors as opposed to the nutritional parameters of blood. While the possibility that initial intraperitoneal growth may have triggered some of the changes in expression observed in mouse blood in vivo, the levels of ply and pspA mRNA are markedly greater in blood at $24 \mathrm{~h}$ compared with blood at $12 \mathrm{~h}$ post-infection.

Given what is known of the functions of the various virulence factors, it is perhaps not surprising that their genes are upregulated in vivo, particularly during the early stages of infection. None of these functions would be expected to confer any advantage on the pneumococcus during in vitro culture. Ply is known to be important for preventing the establishment of early nonspecific host immune responses capable of limiting net exponential growth of pneumococci in the blood (Benton et al., 1995). Thus, high initial levels of expression of ply may be critical. PsaA is a metalbinding lipoprotein with specificity for $\mathrm{Mn}^{2+}$ and possibly also $\mathrm{Zn}^{2+}$ (Dintilhac et al., 1997; Lawrence et al., 1998) and so sustained expression of psaA in vivo is consistent with an ongoing need to scavenge these metal ions from the blood.

The pattern of $p s p A$ expression was an interesting finding of this study. It was the least abundant mRNA species in vitro, but was up-regulated threefold at $12 \mathrm{~h}$ after intraperitoneal infection. One of the known functions of PspA is inhibition of complement-mediated clearance of pneumococci from the blood, by interference with deposition of $\mathrm{C} 3 \mathrm{~b}$ on the bacterial surface (Tu et al., 1999). This property would be expected to be advantageous throughout the infectious process. Indeed, levels of PspA are reported to be higher in opaque variants of pneumococci, a phenotype associated with systemic virulence (Kim \& Weiser, 1998). Remarkably, pspA mRNA levels increased approximately 36-fold at $24 \mathrm{~h}$ post-infection relative to levels detected in serum broth. Conversely, $c b p A$ mRNA levels were similar to in vitro levels at both $12 \mathrm{~h}$ and $24 \mathrm{~h}$ post-infection. CbpA's primary function is believed to be that of an adhesin with an important role in nasopharyngeal colonization, and effects of mutagenesis of $c b p A$ on systemic virulence were reported to be minimal (Gosink et al., 2000; Ring et al., 1998; Rosenow et al., 1997). CbpA has recently been shown to interact with the human polymeric immunoglobulin receptor, thereby facilitating invasion of the mucosa (Zhang et al., 2000). However, we have shown that a $S$. pneumoniae cbpA/ply double mutant has massively attenuated systemic virulence compared with either $c b p A$ or ply single mutants (Berry \& Paton, 2000). These latter findings are consistent with a role for CbpA in the post-adherence/invasion stages of the pathogenic process. Moreover, $\mathrm{CbpA}$ has also recently been shown to be capable of binding to C3 (Smith \& Hostetter, 2000), and Brooks-Walter et al. (1999) have suggested that CbpA and PspA could perform analogous functions in vivo. This is supported by their observation that mutagenesis of $p s p A$ has a much lesser impact on systemic virulence in $S$. pneumoniae strains which contain $\operatorname{cbp} A$ than in those which lack it, implying a degree of functional complementation. Thus, the poor expression of $c b p A$ observed in the present study could be offset by the marked increase in expression of $p s p A$.

The precise manner in which the PS contributes to virulence is not fully understood, although it is known to have strong anti-phagocytic properties in nonimmune hosts (Paton \& Morona, 2000). The capsular PS of the majority of serotypes is highly charged at physiological $\mathrm{pH}$ and this may directly interfere with interactions with phagocytes. Pneumococcal cell wall teichoic acid is capable of activating the alternative complement pathway. In addition, antibodies to this and other cell surface constituents (e.g. surface proteins), which are found in most adult human sera, may result in activation of the classical complement pathway, as does interaction of the teichoic acid with C-reactive protein. However, the PS forms an inert shield, which appears to prevent interaction of either the Fc region of IgG or iC $3 b$ fixed to deeper cell surface structures from interacting with receptors on phagocytic cells (Musher, 1992). Thus, in systemic challenge models such as that used in the present study, maximal expression of PS might be expected to be beneficial to the pneumococcus at all stages of the infection. However, studies in nasopharyngeal colonization models suggest that high encapsulation might interfere with the interaction between other surface molecules (e.g. PspA and CbpA) and the host epithelium (Kim \& Weiser, 1998; Talbot et al., 1996).

We believe this to be the first study in which pneumococcal virulence gene mRNAs have been directly quantified from bacteria present in the blood of infected mice. The only previous study addressing in vivo pneumococcal virulence gene expression examined mRNA levels in type 3 pneumococci grown in sealed dialysis bags implanted in the murine peritoneal cavity (Orihuela et al., 2000). However, this is a suboptimal in vivo surrogate, because it prevents interactions between pathogen and host cells, or host molecules larger than 
the dialysis bag pore size ( $25 \mathrm{kDa}$ cutoff). Using Northern blotting, Orihuela et al. (2000) detected a $2 \cdot 8$-fold stimulation in ply expression at $8 \mathrm{~h}$, compared with bacteria grown in vitro, but intraperitoneal up-regulation of $p s p A$ expression was not detected. Expression of a gene from the type 3 PS biosynthesis locus (cap3A) was also increased $2 \cdot 2$-fold, although we observed slightly higher levels in the present study for $c p s 2 \mathrm{~A}$. We have now demonstrated that $c p s 2 A$ and three of the key virulence protein genes, $p l y, p s p A$ and $p s a A$, are up-regulated in vivo. Moreover, there are marked differences in the patterns of expression of the various genes at different times post-infection, although little is known of the mechanism whereby this occurs. Jakubovics et al. (2000) have recently described a Streptococcus gordonii gene scaR, which encodes a metallorepressor-like protein that regulates the expression of a homologue of PsaA (the Sca $\mathrm{Mn}^{2+}$ permease). A homologue of this gene, designated $p s a R$, is known to be present in the genome of $S$. pneumoniae, but to date a role in regulation of the psa operon has not been demonstrated. Establishing that certain key virulence genes respond to host signals is a major step forward; identifying these as markers will assist in studies of the molecular genetics of virulence gene regulation in this important human pathogen. However, the finding that the relative expression of these virulence genes differed between organisms grown in vitro in serum broth, and those grown in vivo, or in different in vitro media (whole blood or THY broth) suggests that the expression of these genes is highly complex and multifactorial.

\section{ACKNOWLEDGEMENTS}

This work was supported by grants from the National Health and Medical Research Council of Australia, and RIVM, the Netherlands. We thank Adrienne Paton for helpful discussions, Matthew Woodrow and David Miller for technical assistance, and Nicholas Coates for assistance with quantification of RT-PCR products.

\section{REFERENCES}

Alexander, J. E., Lock, R. A., Peeters, C. C. A. M., Poolman, J. T., Andrew, P. W., Mitchell, T. J., Hansman, D. \& Paton, J. C. (1994). Immunization of mice with pneumolysin toxoid confers a significant degree of protection against at least nine serotypes of Streptococcus pneumoniae. Infect Immun 62, 5683-5688.

Austrian, R. (1981). Some observations on the pneumococcus and on the current status of pneumococcal disease and its prevention. Rev Infect Dis 3 (Suppl.), S1-S17.

Avery, O. T., MacLeod, C. M. \& McCarty, M. (1944). Studies on the chemical nature of the substance inducing transformation of pneumococcal types. Induction of transformation by a desoxyribonucleic acid fraction isolated from pneumococcus type III. $J$ Exp Med 79, 137-158.

Bentley, R. W., Leigh, J. A. \& Collins, M. D. (1991). Intrageneric structure of Streptococcus based on comparative analysis of small-subunit rRNA sequences. Int J Syst Bacteriol 41, 487-494.
Benton, K. A., Everson, M. P. \& Briles, D. E. (1995). A pneumolysin-negative mutant of Streptococcus pneumoniae causes chronic bacteremia rather than acute sepsis in mice. Infect Immun 63, 448-455.

Berry, A. M. \& Paton, J. C. (1996). Sequence heterogeneity of PsaA, a $37-\mathrm{kDa}$ putative adhesin essential for virulence of Streptococcus pneumoniae. Infect Immun 64, 5255-5262.

Berry, A. M. \& Paton, J. C. (2000). Additive attenuation of virulence of Streptococcus pneumoniae by mutation of the genes encoding pneumolysin and other putative pneumococcal virulence proteins. Infect Immun 68, 133-140.

Berry, A. M., Yother, J., Briles, D. E., Hansman, D. \& Paton, J. C. (1989). Reduced virulence of a defined pneumolysin-negative mutant of Streptococcus pneumoniae. Infect Immun 57, 20372042.

Berry, A. M., Ogunniyi, A. D., Miller, D. C. \& Paton, J. C. (1999). Comparative virulence of Streptococcus pneumoniae strains with insertion-duplication, point, and deletion mutations in the pneumolysin gene. Infect Immun 67, 981-985.

Boulnois, G. J. (1992). Pneumococcal proteins and the pathogenesis of disease caused by Streptococcus pneumoniae. J Gen Microbiol 138, 249-259.

Boulnois, G. J., Paton, J. C., Mitchell, T. J. \& Andrew, P. W. (1991). Structure and function of pneumolysin, the multifunctional, thiol-activated toxin of Streptococcus pneumoniae. Mol Microbiol 5, 2611-2616.

Briles, D. E., Ades, E., Paton, J. C., Sampson, J. S., Carlone, G. M., Huebner, R. C., Virolainen, A., Swiatlo, E. \& Hollingshead, S. K. (2000a). Intranasal immunization of mice with a mixture of the pneumococcal proteins PsaA and PspA is highly protective against nasopharyngeal carriage of Streptococcus pneumoniae. Infect Immun 68, 796-800.

Briles, D. E., Hollingshead, S., Brooks-Walter, A. \& 7 other authors (2000b). The potential to use PspA and other pneumococcal proteins to elicit protection against pneumococcal infection. Vaccine 18, 1707-1711.

Brooks-Walter, A., Briles, D. E. \& Hollingshead, S. K. (1999). The $p s p C$ gene of Streptococcus pneumoniae encodes a polymorphic protein, PspC, which elicits cross-reactive antibodies to PspA and provides immunity to pneumococcal bacteremia. Infect Immun 67, 6533-6542.

Claverys, J. P., Granadel, C., Berry, A. M. \& Paton, J. C. (1999). Penicillin tolerance in Streptococcus pneumoniae, autolysis and the Psa ATP-binding cassette (ABC) manganese permease. Mol Microbiol 32, 881-883.

Dintilhac, A., Alloing, G., Granadel, C. \& Claverys, J. P. (1997). Competence and virulence of Streptococcus pneumoniae: Adc and PsaA mutants exhibit a requirement for $\mathrm{Zn}$ and $\mathrm{Mn}$ resulting from inactivation of putative $\mathrm{ABC}$ metal permeases. Mol Microbiol 25, 727-739.

Feldman, C., Mitchell, T. J., Andrew, P. W., Boulnois, G. J., Read, R. C., Todd, H. C., Cole, P. J. \& Wilson, R. (1990). The effect of Streptococcus pneumoniae pneumolysin on human respiratory epithelium in vitro. Microb Pathog 9, 275-284.

Ferrante, A., Rowan-Kelly, B. \& Paton, J. C. (1984). Inhibition of in vitro human lymphocyte response by the pneumococcal toxin pneumolysin. Infect Immun 46, 585-589.

Garenne, M., Ronsmans, C. \& Campbell, H. (1992). The magnitude of mortality from acute respiratory infections in children under 5 years in developing countries. World Health Stat Q 46, 180-191.

Gosink, K. K., Mann, E. R., Guglielmo, C., Tuomanen, E. I. \& Masure, H. R. (2000). Role of novel choline binding proteins in 
virulence of Streptococcus pneumoniae. Infect Immun 68, 56905695.

Hammerschmidt, S., Talay, S. R., Brandtzaeg, P. \& Chhatwal, G. S. (1997). SpsA, a novel pneumococcal surface protein with specific binding to secretory immunoglobulin A and secretory component. Mol Microbiol 25, 1113-1124.

Hammerschmidt, S., Bethe, G., Remane, P. H. \& Chhatwal, G. S. (1999). Identification of pneumococcal surface protein $A$ as a lactoferrin-binding protein of Streptococcus pneumoniae. Infect Immun 67, 1683-1687.

Hammerschmidt, S., Tillig, M. P., Wolff, S., Vaerman, J. P. \& Chhatwal, G. S. (2000). Species-specific binding of human secretory component to SpsA protein of Streptococcus pneumoniae via a hexapeptide motif. Mol Microbiol 36, 726-736.

Houldsworth, S., Andrew, P. W. \& Mitchell, T. J. (1994). Pneumolysin stimulates production of tumor necrosis factor alpha and interleukin-1 beta by human mononuclear phagocytes. Infect Immun 62, 1501-1503.

Iannelli, F., Pearce, B. J. \& Pozzi, G. (1999). The type 2 capsule locus of Streptococcus pneumoniae. J Bacteriol 181, 2652-2654.

Jakubovics, N. S., Smith, A. W. \& Jenkinson, H. F. (2000). Expression of the virulence-related Sca $\left(\mathrm{Mn}^{2+}\right)$ permease in Streptococcus gordonii is regulated by a diphtheria toxin metallorepressor-like protein ScaR. Mol Microbiol 38, 140-153.

Kim, J. O. \& Weiser, J. N. (1998). Association of intrastrain phase variation in quantity of capsular polysaccharide and teichoic acid with the virulence of Streptococcus pneumoniae. J Infect Dis 177, 368-377.

Lankinen, K. S., Ruutu, P., Nohynek, H., Lucero, M., Paton, J. C. \& Leinonen, M. (1999). Pneumococcal pneumonia diagnosis by demonstration of pneumolysin antibodies in precipitated immune complexes: a study in 350 Philippine children with acute lower respiratory infection. Scand J Infect Dis 31, 155-161.

Lawrence, M. C., Pilling, P. A., Epa, V. C., Berry, A. M., Ogunniyi, A. D. \& Paton, J. C. (1998). The crystal structure of pneumococcal surface antigen PsaA reveals a metal-binding site and a novel structure for a putative ABC-type binding protein. Structure 6, 1553-1561.

McDaniel, L. S., Yother, J., Vijayakumar, M., McGarry, L., Guild, W. R. \& Briles, D. E. (1987). Use of insertional inactivation to facilitate studies of biological properties of pneumococcal surface protein A (PspA). J Exp Med 165, 381-394.

Mitchell, T. J., Andrew, P. W., Saunders, F. K., Smith, A. N. \& Boulnois, G. J. (1991). Complement activation and antibody binding by pneumolysin via a region of the toxin homologous to a human acute-phase protein. Mol Microbiol 5, 1883-1888.

Mortier-Barrière, I., de Saizieu, A., Claverys, J. P. \& Martin, B. (1998). Competence-specific induction of recA is required for full recombination proficiency during transformation in Streptococcus pneumoniae. Mol Microbiol 27, 159-170.

Musher, D. M. (1992). Infections caused by Streptococcus pneumoniae: clinical spectrum, pathogenesis, immunity, and treatment. Clin Infect Dis 14, 801-809.

Novak, R., Braun, J. S., Charpentier, E. \& Tuomanen, E. (1998). Penicillin tolerance genes of Streptococcus pneumoniae: the ABCtype manganese permease complex Psa. Mol Microbiol 29, 1285-1296.

Obaro, S. K. (2000). Prospects for pneumococcal vaccination in African children. Acta Trop 75, 141-153.

Ogunniyi, A. D., Folland, R. L., Briles, D. E., Hollingshead, S. K. \& Paton, J. C. (2000). Immunization of mice with combinations of pneumococcal virulence proteins elicits enhanced protection against challenge with Streptococcus pneumoniae. Infect Immun 68, 3028-3033.

Orihuela, C. J., Janssen, R., Robb, C. W., Watson, D. A. \& Niesel, D. W. (2000). Peritoneal culture alters Streptococcus pneumoniae protein profiles and virulence properties. Infect Immun 68, 6082-6086.

Paton, J. C. (1996). The contribution of pneumolysin to the pathogenicity of Streptococcus pneumoniae. Trends Microbiol 4, 103-106.

Paton, J. C. (1998). Novel pneumococcal surface proteins: role in virulence and vaccine potential. Trends Microbiol 6, 85-87.

Paton, J. C. \& Ferrante, A. (1983). Inhibition of human polymorphonuclear leukocyte respiratory burst, migration and bactericidal activity by the pneumococcal toxin, pneumolysin. Infect Immun 41, 1212-1216.

Paton, J. C. \& Morona, J. K. (2000). Streptococcus pneumoniae capsular polysaccharide. In Gram-Positive Pathogens, pp. 201213. Edited by V. A. Fischetti, R. Novick, J. Ferretti, D. Portnoy \& J. Rood. Washington, DC: American Society for Microbiology.

Paton, J. C., Rowan-Kelly, B. \& Ferrante, A. (1984). Activation of human complement by the pneumococcal toxin, pneumolysin. Infect Immun 43, 1085-1087.

Paton, J. C., Andrew, P. W., Boulnois, G. J. \& Mitchell, T. J. (1993). Molecular analysis of the pathogenicity of Streptococcus pneumoniae: the role of pneumococcal proteins. Annu Rev Microbiol 47, 89-115.

Paton, J. C., Berry, A. M. \& Lock, R. A. (1997). Molecular analysis of putative pneumococcal virulence proteins. Microb Drug Resist 3, 1-10.

Rapola, S., Jantti, V., Haikala, R. \& 8 other authors (2000). Natural development of antibodies to pneumococcal surface protein A, pneumococcal surface adhesin A, and pneumolysin in relation to pneumococcal carriage and acute otitis media. J Infect Dis 182, 1146-1152.

Ring, A., Weiser, J. N. \& Tuomanen, E. I. (1998). Pneumococcal trafficking across the blood-brain barrier. Molecular analysis of a novel bidirectional pathway. J Clin Invest 102, 347-360.

Rosenow, C., Ryan, P., Weiser, J. N., Johnson, S., Fontan, P., Ortqvist, A. \& Masure, H. R. (1997). Contribution of novel cholinebinding proteins to adherence, colonization and immunogenicity of Streptococcus pneumoniae. Mol Microbiol 25, 819-829.

Smith, B. L. \& Hostetter, M. K. (2000). C3 as substrate for adhesion of Streptococcus pneumoniae. J Infect Dis 182, 497-508.

Talbot, U., Paton, A. W. \& Paton, J. C. (1996). Uptake of Streptococcus pneumoniae by respiratory epithelial cells. Infect Immun 64, 3772-3777.

Tu, A. H., Fulgham, R. L., McCrory, M. A., Briles, D. E. \& Szalai, A. J. (1999). Pneumococcal surface protein A inhibits complement activation by Streptococcus pneumoniae. Infect Immun 67, 4720-4724.

Tuomanen, E. I., Austrian, R. \& Masure, H. R. (1995). The pathogenesis of pneumococcal infection: correlation of clinical events with molecular mechanisms. N Engl J Med 332, 1280-1284.

Virolainen, A., Russell, W., Crain, M. J., Rapola, S., Kayhty, H. \& Briles, D. E. (2000). Human antibodies to pneumococcal surface protein A in health and disease. Pediatr Infect Dis J 19, 134-138.

Walker, J. A., Allen, R. L., Falmagne, P., Johnson, M. K. \& Boulnois, G. J. (1987). Molecular cloning, characterization, and complete nucleotide sequence of the gene for pneumolysin, the sulfhydryl-activated toxin of Streptococcus pneumoniae. Infect Immun 55, 1184-1189. 
Whitney, C. G., Farley, M. M., Hadler, J. \& 10 other authors (2000). Increasing prevalence of multidrug-resistant Streptococcus pneumoniae in the United States. N Engl J Med 343, 1917-1924.

World Health Organization (1997). Global Programme for Vaccines and Immunization (Vaccine Research and Development). Report of The Technical Review Group Meeting, July 1997-June 1998; Achievements and Plan of Activities: Meningococcal and Pneumococcal Disease Vaccines, pp. 26-30. Geneva, Switzerland: WHO.

Yother, J. \& Briles, D. E. (1992). Structural properties and evolutionary relationships of PspA, a surface protein of Streptococcus pneumoniae, as revealed by sequence analysis. $J$ Bacteriol 174, 601-609.

Zhang, J. R., Mostov, K. E., Lamm, M. E., Nanno, M., Shimida, S., Ohwaki, M. \& Tuomanen, E. (2000). The polymeric immunoglobulin receptor translocates pneumococci across human nasopharyngeal epithelial cells. Cell 102, 827-837.

Received 13 February 2002; revised 25 March 2002; accepted 27 March 2002. 